\title{
Severity of erectile dysfunction is highly correlated with the syntax score in patients undergoing coronariography
}

Weslley Santiago Andrade ${ }^{1}$, Paulo Oliveira ${ }^{2}$, Humberto Laydner ${ }^{3}$, Eduardo Jose Pereira Ferreira ${ }^{1}$, Jose Augusto Soares Barreto-Filho ${ }^{1}$

${ }^{1}$ Universidade Federal de Sergipe, Aracaju, Sergipe, Brazil, ${ }^{2}$ Universidade Estadual de Feira de Santana, Feira de Santana, Bahia, Brazil, ${ }^{3}$ University Hospitals-Urology, Cleveland, OH, USA

\section{ABSTRACT}

Objective: To investigate the association between the severity of erectile dysfunction (ED) and coronary artery disease (CAD) in men undergoing coronary angiography for angina or acute myocardial infarct (AMI).

Material and Methods: We studied 132 males who underwent coronary angiography for first time between January and November 2010. ED severity was assessed by the international index of erectile function (IIEF-5) and CAD severity was assessed by the Syntax score. Patients with CAD (cases) and without CAD (controls) had their IIEF-5 compared. In the group with CAD, their IIEF-5 scores were compared to their Syntax score results.

Results: We identified 86 patients with and 46 without CAD. The IIEF-5 score of the group without CAD $(22.6 \pm 0.8)$ was significantly higher than the group with CAD $(12.5 \pm 0.5 ; p<0.0001)$. In patients without ED, the Syntax score average was $6.3 \pm 3.5$, while those with moderate or severe ED had a mean Syntax score of 39.0 \pm 11.1 . After adjustment, ED was independently associated to CAD, with an odds ratio of 40.6 (CI $95 \%, 14.3-115.3, \mathrm{p}<0.0001)$. The accuracy of the logistic model to correctly identify presence or absence of CAD was $87 \%$, with 92\% sensitivity and 78\% specificity. The average time that ED was present in patients with CAD was $38.8 \pm 2.3$ months before coronary symptoms, about twice as high as patients without CAD (18.0 \pm 5.1 months). Conclusions: ED severity is strongly and independently correlated with CAD complexity, as assessed by the Syntax score in patients undergoing coronariography for evaluation of new onset coronary symptoms.

\section{ARTICLE INFO}

Key words:

Erectile Dysfunction;

Coronary Angiography; Patients

Int Braz J Urol. 2016; 42: 123-31

Submitted for publication:

January 01, 2015

Accepted after revision:

July 17, 2015

\section{INTRODUCTION}

Atherosclerosis is a multifactorial chronic inflammatory disease which occurs as a response to endothelial damage, affecting mostly the intimal layer of multiple diameter arteries. In at least half of the patients, the first presentation of atherosclerotic disease is an acute coronary event. In $68 \%$ of sudden deaths, patients did not have previous symptoms of coronary heart disease (1). There is a huge effort worldwide for early detection of coronary artery disease (CAD), due to its elevated morbidity and mortality rates as well as significant social-economics consequences. It is 
estimated that atherothrombotic events will continue to be the leading cause of death as far as 2020 (2).

Although invasive and requiring highly specialized physics, equipment and personnel structure, the gold standard test to determine the presence and severity of CAD is coronariography. The Syntax score developed for the SYNTAX trial (Synergy Between PCI with Taxus and Cardiac Surgery) presents a thorough way to analyze the severity of CAD $(3,4)$.

Erectile dysfunction (ED) is the inability to achieve and maintain erection for satisfactory sexual intercourse (5) and its global prevalence ranges from 2 to $86 \%$ (6). ED has risk factors and physiopathology basis similar to those of CAD, with endothelial dysfunction as a common denominator affecting several vascular beds of multiple diameters (7). ED can be easily assessed by using the abridged International Index of Erectile Function (IIEF-5) questionnaire (8). Besides affecting sexuality, ED has been increasingly recognized for its ability to detect insidious $\operatorname{CAD}(9,10)$.

There is no non-invasive method, clinical sign or laboratory test capable of detecting all individuals who will develop CAD. ED may be an early clinical marker of CAD with association to the degree of ED and the severity of coronary artery disease in a large portion of men. Herein, we evaluated the association between the complexity of CAD measured by the Syntax score and the severity of ED measured by the IIEF-5 in men who underwent coronary angiography.

\section{MATERIAL AND METHODS}

Male patients undergoing coronary angiography for the first time between January and November 2010 were included in this case-control study. During this period, 1773 patients underwent coronary angiography. Based on convenience sampling, 132 patients consecutively submitted to first coronary angiography for diagnosis of CAD were selected according to the following criteria: age between 40 and 70 years old, hemodynamic stability, full recovery from the procedure with consciousness and orientation (average recovery time of 3 hours after the procedure), at least 2 risk factors for CAD [hypertension, dyslipidemia, hyperglycemia, smoking, family history of stroke, or acute myocardial infarction (AMI)], absence of previous cardiovascular events (first event).

Exclusion criteria were: ED after radical prostatectomy, ED secondary to a neurological lesion, refusal to participate in the study. Five patients were excluded because they were not fully recovered from the procedure.

Patients were clinically evaluated and filled both a demographic and the IIEF-5 questionnaires. The recorded coronariography films were analyzed with the Syntax Score to evaluate the complexity of the coronary lesions by an experienced cardiologist who was blind to the patient's erectile function status. The SYNTAX score is the sum of the points assigned to each individual lesion with $>50 \%$ diameter narrowing in vessels $>1.5 \mathrm{~mm}$ diameter in the coronary tree. A computer algorithm is then queried and a summed value is generated.

Patients were divided into two groups according to the exam results: Group-1 (test) had obstruction equal to or greater than 50\% of the vessel lumen and Group-2 (control) without CAD detected on coronariography. Patients on Group-2 should have at least one additional exam, such as stress test, stress echocardiography, or myocardial scintigraphy to rule out CAD.

Group-2 patients were further classified according to their indication for the exam in acute (unstable angina, AMI) or chronic (stable angina) cases. The duration of ED was considered in relation to the first coronary symptom.

The IIEF-5 questionnaire was given after the patient fully recovered from the angiographic procedure. The IIEF- 5 ranges from 5 to 25 points, classifying ED into one of five possible categories: severe (5-7 points), moderate (8-11), mild to moderate (12-16), mild (17-21), and absence of ED (22-25). The IIEF-5 questions refer to the patient's symptoms in the previous 6 months and not only to the moment when they are answering the questions.

This study was approved by the ethics committee of our Institution under the protocol number 1274.0.000.107-09. Patients were included in the study only after informed consent was obtained. 


\section{Statistical analysis}

The continuous and categorical variables were described as averages with standard deviation and frequencies with 95\% confidence interval, respectively. The Shapiro-Wilk test was used to evaluate the assumption of normality. We used either the Pearson Chi-square or the Fisher's exact test when appropriate to test the hypothesis relative to categorical variables. The Student's t-test for independent samples was used for the comparison between groups with $\mathrm{CAD}$ and without $\mathrm{CAD}$. The comparison of the variable "SYNTAX score" between the groups with different degrees of ED was performed with analysis of variance (ANOVA) followed by the Tukey post-hoc. The comparison of the variable "IIEF-5" between the test and control groups was performed with a general linear model with a single factor (group) adjusted for the variables "age" and "use of diuretics". The forward stepwise logistic regression method was used to evaluate ED as a predictor of CAD. The ability of the model to discriminate patients with $\mathrm{CAD}$ and without $\mathrm{CAD}$ with the receiver operating characteristic (ROC) curve was also analyzed. The ability of the ROC curve to discriminate between cases with CAD and without CAD for the variable "IIEF-5" was also evaluated. The $p$ value of 0.05 was considered significant. The SPSS software version $18.0^{\circledR}$ was used for statistical analysis.

\section{RESULTS}

We evaluated 132 male patients, 86 with CAD and 46 without CAD. Patient's characteristics

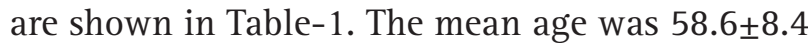
years. Hypertension and diabetes were present in $95.4 \%$ and $31 \%$ of the patients, respectively. The test and control groups were significantly different regarding mean age, use of diuretics, and IIEF-5 ( $\mathrm{p}=0.02, \mathrm{p}<0.0001$, and $\mathrm{p}<0.0001$, respectively). The IIEF- 5 score of the group without CAD (adjusted mean 22.6 \pm 0.8 ) was significantly higher than the score of the group with CAD (adjusted mean $12.5 \pm 0.5$ ) after adjustment for age and use of diuretics, with an average difference of $10.1 \pm 0.9$ (IC 95\%, 8.2-12.0, $\mathrm{p}<0.0001$ ) between the groups (Figure-1). ED was present in 89 patients (67.4\%), $46 \%$ of which were moderate or severe (Table-2).
In the 86 patients with CAD, the Syntax score averages increased exponentially with increasing severity of ED. In patients with normal erectile function, the Syntax score average was $6.3 \pm 3.5$, while those patients with moderate or severe ED had a mean Syntax score of 39.0 111.1 (Figure-2).

After adjustment for age, total cholesterol, LDL cholesterol, and triglycerides, ED was the only variable independently associated to $\mathrm{CAD}$, with odds ratio of 40.6 (CI 95\%, 14.3-115.3, p<0.0001). The accuracy of the logistic model to correctly identify the presence or absence of CAD was $87.1 \%$ after adjustment, with sensibility of 91.9\% and specificity of 78.3\% for diagnosis of CAD. The area under the ROC curve was $0.851 \pm 0.040$ $(\mathrm{p}<0.001$, CI 95\%, 0.773-0.929), demonstrating a good discriminant ability (Table-3).

The IIEF-5 questionnaire had an exceptional discriminant ability for presence or absence of CAD (area under the ROC curve 0.922 \pm 0.022 , $\mathrm{p}<0.001$ ), with sensibility of $91.2 \%$, specificity of $78.3 \%$, and an IIEF-5 cutoff value of 21.5 (Figure-3).

The average time that ED was present in patients with $\mathrm{CAD}$ was $38.8 \pm 2.3$ months before the coronariography. The average time of ED in patients with acute disease was $38.4 \pm 19.2$ months (Table-4).

\section{DISCUSSION}

In our study, the IIEF-5 questionnaire had exceptional discriminant ability for the diagnosis of CAD, when compared with the Syntax score. We identified a clear correlation between the severity of $\mathrm{ED}$ and the complexity of $\mathrm{CAD}$, which has been previously observed in the literature (1113). However, the method that we used to evaluate the complexity of coronary disease differed from those used by other authors. Greenstein et al. used the number of vessels with at least one significant lesion. They found that patients with a single vessel affected had erections more frequently, more rigid, and more easily to achieve than patients with 2 or 3 vessels affected (11). Montorsi et al. used the Gensini's score, which estimates the amount of myocardium affected by each coronary 
Table 1 - Baseline characteristics.

\begin{tabular}{|c|c|c|c|}
\hline & $\begin{array}{l}\text { Group } 1(n=86) \\
\text { (with CAD) }\end{array}$ & $\begin{array}{c}\text { Group } 2(n=46) \\
\text { (without } C A D)\end{array}$ & $P$ value \\
\hline Age & $59.8 \pm 8.2$ & $56.3 \pm 8.8$ & $=0.02$ \\
\hline Sistolic BP & $156.5 \pm 19.0$ & $154.7 \pm 17.4$ & 0.6 \\
\hline Diastolic BP & $92.7 \pm 9.4$ & $92.5 \pm 9.0$ & 0.9 \\
\hline BMI & $27.2 \pm 3.1$ & $27.1 \pm 4.2$ & 0.9 \\
\hline$A C$ & $103.0 \pm 20.1$ & $99.0 \pm 10 ., 8$ & 0.2 \\
\hline Glucose & $107.9 \pm 39.8$ & $107.9 \pm 39.7$ & 0.9 \\
\hline Total cholesterol & $214.3 \pm 48.6$ & $199.4 \pm 72.4$ & 0.2 \\
\hline HDL & $39.5 \pm 7.4$ & $41.0 \pm 9.6$ & 0.2 \\
\hline LDL & $139.0 \pm 42.8$ & $125.8 \pm 64.0$ & 0.2 \\
\hline Triglycerids & $178.7 \pm 68.3$ & $160.1 \pm 69.2$ & 0.2 \\
\hline Total IIEF-5 & $12.7 \pm 5.7$ & $22.03 \pm 2.3$ & $<0.0001$ \\
\hline Smoking & $48(55.8 \%)$ & $21(45.7 \%)$ & 0.3 \\
\hline Family history of stroke & $28(32.6 \%)$ & $12(26.1 \%)$ & 0.6 \\
\hline Family history of CVD & $30(34.9 \%)$ & $15(32.6 \%)$ & 0.8 \\
\hline Hypertension & $82(95.3 \%)$ & $44(95.7 \%)$ & 0.9 \\
\hline Diabetes Mellitus & $29(33.7 \%)$ & $12(26.1 \%)$ & 0.4 \\
\hline \multicolumn{4}{|l|}{ ETHNICITY } \\
\hline White & $66(76.74 \%)$ & $32(69.57 \%)$ & 0.4 \\
\hline No-White & $14(23.26 \%)$ & $20(30.43 \%)$ & 0.4 \\
\hline \multicolumn{4}{|l|}{ MEDICATIONS IN USE } \\
\hline Diuretics & $15(17.4 \%)$ & $25(54.3 \%)$ & $<0.0001$ \\
\hline Adrenergic inhibitors & $44(51.2 \%)$ & $21(45.7 \%)$ & 0.6 \\
\hline Vasodilators & $18(20.9 \%)$ & $07(15.2 \%)$ & 0.5 \\
\hline CCB & $09(10.5 \%)$ & $08(17.4 \%)$ & 0.3 \\
\hline ACE Inhibitors & $31(36.0 \%)$ & $18(39.1 \%)$ & 0.8 \\
\hline ARB & $13(15.1 \%)$ & $11(23.9 \%)$ & 0.2 \\
\hline
\end{tabular}

$\mathbf{H D L}=$ high density lipoprotein; $\mathbf{L D L}=$ low density lipoprotein; $\mathbf{C V D}=$ cardiovascular disease; $\mathbf{B M I}=$ body mass index; $\mathbf{A C}=$ abdominal circunference; $\mathbf{C C B}=$ calcium channel blockers; $\mathbf{A C E}=$ angiotensin-converting enzyme; $\mathbf{A R B}=$ angiotensina II receptor blockers 
Figure 1 - IIEF-5 versus Coronary Artery Disease

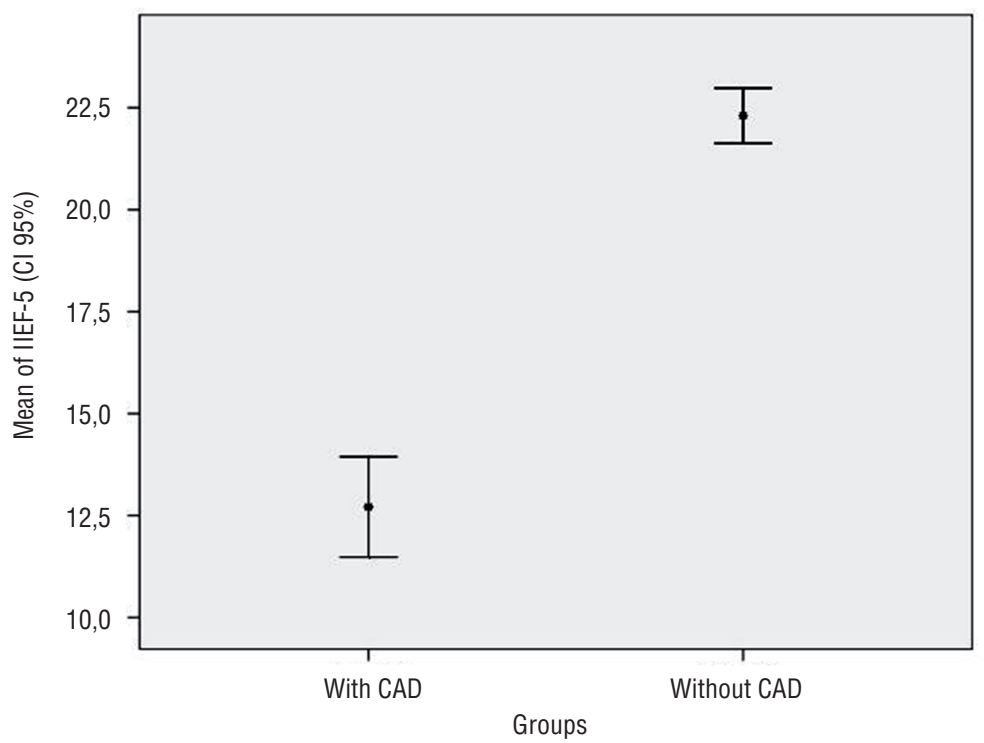

Table 2 - Erectile dysfunction severity (IIEF-5).

\begin{tabular}{lcc}
\hline Erectyle dysfunction severity & $\mathrm{n}(\%)$ & $\mathrm{Cl} 95 \%$ \\
\hline No ED & $43(32.6 \%)$ & $25.0-40.2$ \\
Mild ED & $28(21.2 \%)$ & $14.4-28.0$ \\
Mild to moderate ED & $20(15.2 \%)$ & $9.1-21.2$ \\
Moderate ED & $19(14.4 \%)$ & $8.3-20.5$ \\
Severe ED & $22(16.7 \%)$ & $10.6-23.5$ \\
\hline
\end{tabular}

Figure 2 - Grade of ED according to Syntax Score

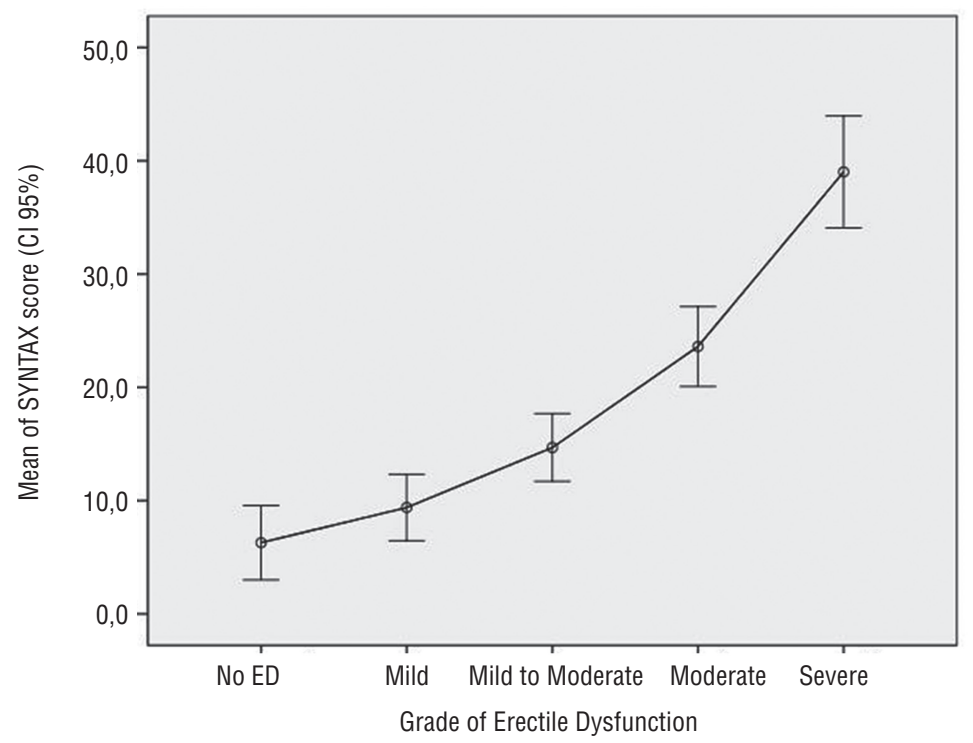


Table 3 - Factors associated with CAD.

\begin{tabular}{lccc}
\hline Variable & $\begin{array}{l}\text { Odds ratio } \\
\text { (adjusted) }\end{array}$ & Cl 95\% & P \\
\hline Age & - & - & 0.55 \\
Total cholesterol & - & - & 0.83 \\
LDL & - & - & 0.98 \\
Triglycerids & - & - & 0.82 \\
Smoking & - & - & 0.78 \\
Erectile Dysfunction & 40.6 & $14.3-115.3$ & $<0.0001$ \\
\hline
\end{tabular}

Figure 3 - ROC curve of IIEF-5 and CAD

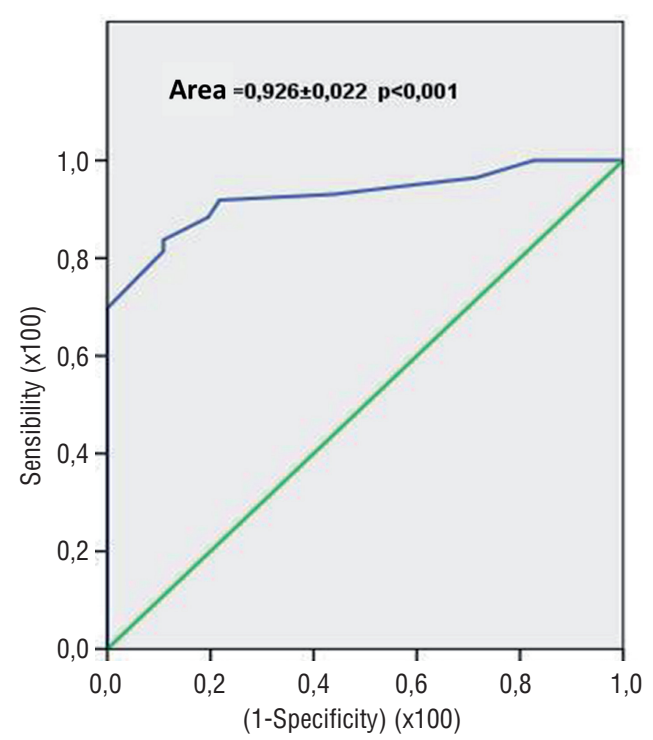

lesion. They identified a significant increase of the Gensini's score proportional to the decrease of the IIEF-5 score (14).

To our knowledge, this is the first study to use the Syntax score as the instrument to evaluate the complexity of coronary lesions in patients with ED. The Syntax was developed as a comprehensive angiographic scoring system aiming to assist in patient selection and risk stratification of patients with extensive coronary artery disease undergoing revascularization with either percutaneous coronary intervention (PCI) or coronary-artery bypass grafting (CAPG) (15). According to the characteristics of the lesions, the SYNTAX score is able to identify patients who are good candidates for PCI, classifying them into low risk (0-22 points), intermediate risk (23-32 points), and high risk ( $\geq 33$ points) patients. It is also a good predictor of adverse events in patients with multiarterial coronary disease and/or with lesions in the left

Table 4 - Time with Erectile Dysfunction $(\mathrm{n}=89$ ).

\begin{tabular}{lccc}
\hline Groups & Time (months) & Cl 95\% & P \\
\hline Without DAC & $18.0 \pm 5.1$ & $7.9-28.1$ & $<0.0001$ \\
With DAC & $38.8 \pm 2.3$ & $34.4-43.3$ & \\
Acute cases* $^{*}$ & $38.4 \pm 19.2$ & & 0.76 \\
Chronic cases $^{*}$ & $39.9 \pm 22.9$ & & \\
\hline
\end{tabular}

* First acute myocardial infarction (AMI) episode, AMI without ST segment elevation or unstable angina; **Stable Angina or thoracic discomfort for $>2$ months 
coronary artery main trunk who underwent PCI. Hence, this instrument has a good discriminatory power for risk assessment (16).

The highly significant correlation that we found between an increased Syntax score and a decreased IIEF-5 score suggests that the ED severity may be an important factor to be assessed before the indication of myocardial revascularization, either by PCI or CABG, which needs to be confirmed in a study designed for this purpose.

The IIEF-5 is widely used because of its easy application and reproducibility. It has a sensibility of 98\% and specificity of 88\% $(8,17)$.

In our study, we did not find any significant difference in the presence of ED between acute and chronic cases. Montorsi et al. found a different prevalence of ED between patients with acute and chronic $\mathrm{CAD}$, with a lower $\mathrm{ED}$ rate in acute cases (14).

The fact that we did not reproduce this finding could be possibly explained by the limited number of chronic cases in our study.

In our study, the mean time interval between the onset of ED and coronary symptom was 38.8 months in the group with CAD, more than two times greater than in the control group (18 months). Montorsi et al. found similar numbers in a previous study with 300 men with acute chest pain in whom ED symptoms became clinically evident prior to CAD symptoms in 67\% of the patients. They also observed a mean time interval between the onset of ED and CAD of 38.8 months (18).

There is evidence of association between penile vascular alterations and abnormalities in the stress test of asymptomatic individuals (1921). For this reason, all patients included in the control group of our study were required to have, besides the coronariography, at least one exam (stress test, stress echocardiography, or myocardial scintigraphy) to rule out ischemic heart disease.

ED and CAD share common risk and etiology factors, with atherosclerosis and endothelial dysfunction promoting vascular insufficiency (22). ED is as a highly sensitive, specific, and accurate marker for potential cardiovascular events. A meta-analysis of 7 cohort studies with 45.558 patients showed an adjusted relative risk of 1.47 (95\% CI, 1.29-1.66, $\mathrm{P}<0.001$ ) for
CVD events in patients with ED in comparison with healthy subjects (23).

Age and use of diuretics were the only ED risk factors that differed significantly between the groups. Both are well known risk factors for ED $(24,25)$. However, the difference of the average IIEF-5 scores between the groups with and without CAD persisted significant even after adjustment for those variables. Riedner et al. observed that men younger than 60 years old with ED are at increased risk for more severe $\mathrm{CAD}$, independently of risk factors for ED and CAD (26).

Limitations of this study include its retrospective nature, which inherently has the potential for selection bias, lack of penile Doppler ultrasound or testosterone levels. Also, the study was conducted in a specific population who carried, at least, two risk factors for atherosclerosis and had an indication for coronary angiography for a clinical suspicion. Hence, its results should be further verified for external validation. Nevertheless, our results associated to the substantial evidence in the literature strongly suggests that the simple assessment of ED severity with a validated tool should not be neglected in the daily practice, as it may aid in the early diagnosis of CAD and prevention of morbidity and mortality associated to coronary disease. The IIEF-5 is an inexpensive and easily applicable tool that may aid in the decision to perform screening exams for CAD in men without coronary symptoms. This holds true especially for patients with other risk factors for CAD. Application of this tool is particularly useful in the daily practice, where methods to detect latent cardiovascular events are extremely important. Health professionals in general should consider ED as a significant medical condition and run a thorough clinical evaluation looking for cardiovascular risk factors. The time when patients first complain of ED may represent a timely window for the early diagnosis and treatment of cardiovascular disease.

\section{CONCLUSIONS}

The severity of ED as assessed by the IIEF5 is strongly and independently correlated with the Syntax score in patients undergoing coronariography for evaluation of new onset coronary 
symptoms. This study further confirms the importance of ED and the IIEF-5 questionnaire for the early identification of patients at increased risk for $\mathrm{CAD}$, which could elicit measures to prevent major cardiovascular events in this population. More studies are needed to determine whether application of the IIEF- 5 could also be extended to a general population without other CAD risk factors.

\section{CONFLICT OF INTEREST}

None declared.

\section{REFERENCES}

1. Ni H, Coady S, Rosamond W, Folsom AR, Chambless L, Russell SD, et al. Trends from 1987 to 2004 in sudden death due to coronary heart disease: the Atherosclerosis Risk in Communities (ARIC) study. Am Heart J. 2009; 157:46-52.

2. Murray CJ, Lopez AD. Alternative projections of mortality and disability by cause 1990-2020: Global Burden of Disease Study. Lancet. 1997; 349:1498-504.

3. Kappetein AP, Head SJ, Morice MC, Banning AP, Serruys PW, Mohr FW, et al. Treatment of complex coronary artery disease in patients with diabetes: 5-year results comparing outcomes of bypass surgery and percutaneous coronary intervention in the SYNTAX trial. Eur J Cardiothorac Surg. 2013; 43:1006-13.

4. Kappetein AP, Dawkins KD, Mohr FW, Morice MC, Mack MJ, Russell ME, et al. Current percutaneous coronary intervention and coronary artery by-pass grafting practices for three-vessel and left main coronary artery disease. Insights from the SYNTAX run-in phase. Eur J Cardiothorac Surg. 2006; 29:486-91.

5. NIH Consensus Conference. Impotence. NIH Consensus Development Panel on Impotence. JAMA. 1993; 270:83-90.

6. Prins J, Blanker MH, Bohnen AM, Thomas S, Bosch JL. Prevalence of erectile dysfunction: a systematic review of population-based studies. Int J Impot Res. 2002; 14:422-32.

7. Reriani M, Flammer AJ, Li J, Prasad M, Rihal C, Prasad A, et al. Microvascular endothelial dysfunction predicts the development of erectile dysfunction in men with coronary atherosclerosis without critical stenoses. Coron Artery Dis. 2014; 25:552-7.

8. Rosen RC, Cappelleri JC, Smith MD, Lipsky J, Peña BM. Development and evaluation of an abridged, 5-item version of the International Index of Erectile Function (IIEF-5) as a diagnostic tool for erectile dysfunction. Int J Impot Res. 1999; 11:319-26.
9. Chew KK, Finn J, Stuckey B, Gibson N, Sanfilippo F, Bremner A, et al. K. Erectile dysfunction as a predictor for subsequente atherosclerotic cardiovascular events: findings from a linked-data study. J Sex Med. 2010; 7:192-202.

10. Thompson IM, Tangen CM, Goodman PJ, Probstfield JL, Moinpour CM, Coltman CA. Erectile dysfunction and subsequent cardiovascular disease. JAMA. 2005; 294:2996-3002.

11. Greenstein A, Chen J, Miller H, Matzkin H, Villa Y, Braf Z. Does severity of ischemic coronary disease correlate with erectile function? Int J Impot Res. 1997; 9:123-6.

12. Canat L, Cicek G, Atis G, Gurbuz C, Caskurlu T. Is there a relationship between severity of coronary artery disease and severity of erectile dysfunction? Int Braz J Urol. 2013; 39:465-73.

13. Foroutan SK, Rajabi M. Erectile dysfunction in men with angiographically documented coronary artery disease. Urol J. 2007; 4:28-32.

14. Montorsi P, Ravagnani PM, Galli S, Rotatori F, Veglia F, Briganti $A$, et al. Association between erectile dysfunction and coronary artery disease. Role of coronary clinical presentation and extent of coronary vessels involvement: the COBRA trial. Eur Heart J. 2006; 27:2632-9.

15. Serruys PW, Morice MC, Kappetein AP, Colombo A, Holmes $\mathrm{DR}$, Mack MJ, et al. Percutaneous coronary intervention versus coronary-artery bypass grafting for severe coronary artery disease. N Engl J Med. 2009; 360:961-72. Erratum in: N Engl J Med. 2013; 368:584.

16. Farooq V, Head SJ, Kappetein AP, Serruys PW. Widening clinical applications of vthe SYNTAX Score. Heart. 2014; 100:276-87.

17. Rhoden EL, Telöken C, Sogari PR, Vargas Souto CA. The use of the simplified International Index of Erectile Function (IIEF-5) as a diagnostic tool to study the prevalence of erectile dysfunction. Int J Impot Res. 2002; 14:245-50.

18. Montorsi F, Briganti A, Salonia A, Rigatti P, Margonato A, Macchi $A$, et al. Erectile dysfunction prevalence, time of onset and association with risk factors in 300 consecutive patients with acute chest painand angiographically documented coronary artery disease. Eur Urol. 2003; 44:360-4.

19. Mulhall J, Teloken P, Barnas J. Vasculogenic erectile dysfunction is a predictor of abnormal stress echocardiography. J Sex Med. 2009; 6:820-5.

20. Vlachopoulos C, Rokkas K, loakeimidis N, Aggeli C, Michaelides A, Roussakis G, etal. Prevalence of asymptomatic coronary artery disease in men with vasculogenic erectile dysfunction: a prospective angiographic study. Eur Urol. 2005; 48:996-1002.

21. Corona G, Fagioli G, Mannucci E, Romeo A, Rossi M, Lotti $F$, et al. Penile doppler ultrasound in patients with erectile dysfunction (ED): role of peak systolic velocity measured in the flaccid state in predicting arteriogenic ED and silent coronary artery disease. J Sex Med. 2008; 5:2623-34. 
22. Gandaglia G, Briganti A, Jackson G, Kloner RA, Montorsi $F$, Montorsi $P$, et al. A systematic review of the association between erectile dysfunction and cardiovascular disease. Eur Urol. 2014; 65:968-78.

23. Guo W, Liao C, Zou Y, Li F, Li T, Zhou Q, et al. Erectile dysfunction and risk of clinical cardiovascular events: a meta-analysis of seven cohort studies. J Sex Med. 2010; 7:2805-16.

24. Manolis A, Doumas M. Antihypertensive treatment and sexual dysfunction. Curr Hypertens Rep. 2012; 14:285-92.
25. Nicolosi A, Buvat J, Glasser DB, Hartmann U, Laumann EO, Gingell C; GSSAB Investigators' Group. Sexual behaviour, sexual dysfunctions and related help seeking patterns in middle-aged and elderly Europeans: the global study of sexual attitudes and behaviors. World J Urol. 2006; 24:423-8.

26. Riedner CE, Rhoden EL, Fuchs SC, Wainstein MV, Gonçalves SC, Wainstein RV, et al. Erectile dysfunction and coronary artery disease: an association of higher risk in younger men. J Sex Med. 2011; 8:1445-53.

Correspondence address:

Paulo Oliveira, MD

Universidade Estadual de Feira de Santana - Medicina

Avenida Transnordestina, S/N Feira de Santana, Bahia 44036-900, Brasil 